\title{
An early warning system for groundwater flooding in the Chalk
}

\author{
B. Adams ${ }^{1}$, J.P. Bloomfield ${ }^{1}$,, A.J. Gallagher ${ }^{1}$, C.R. Jackson $^{2}$, H.K. Rutter ${ }^{1}$ \& \\ A.T. Williams ${ }^{1}$ \\ ${ }^{1}$ British Geological Survey, Maclean Building, Wallingford, Oxfordshire OX10 8BB, UK \\ ${ }^{2}$ British Geological Survey, Kingsley Dunham Centre, Keyworth, Nottingham NG12 5GG UK
}

\begin{abstract}
An early warning system has been developed for groundwater flooding and trialled in the Patcham area of Brighton. It provides a fit-for-purpose approach for forecasting groundwater flood events in the Chalk and is capable of operating across longer time scales than had previously been possible. The method involves a set of nested steps or tasks. Initially, the catchment's response to recharge is determined and, using a representative hydrograph, a simple regression model that relates annual groundwater level minima and autumn and winter rainfall to subsequent annual maxima is developed. The regression model is then applied at the end of each summer recession using the observed annual minimum and estimates of winter rainfall to predict the following groundwater level maximum. Based on the results of this prediction a variety of steps may then be appropriate. Where the model predicts potentially high groundwater levels the frequency of groundwater level monitoring observations can be increased. A novel element of the method developed is the monitoring of changes in the matric potential of the unsaturated zone. Specific trigger levels to initiate either the next step of the method or promulgation of warnings of varying severity will be developed through experience of use of the system.
\end{abstract}

\section{Introduction}

The floods that affected large parts of SE England and northern France in the winter of 2000-2001 were due to groundwater flooding on the Chalk aquifer (Robinson et al. 2001; Pinault et al. 2005). The floods caused significant disruption and damage to infrastructure and livelihoods. Fit-for-purpose early warning systems for fluvial flooding in England and Wales, managed by the Environment Agency, are extensively employed. However, early warning systems for groundwater flooding are much less common because of the relative lack of information on groundwater flooding events and because the phenomenon is poorly understood. Unlike fluvial flooding, groundwater flooding has received very little attention in the peer-reviewed literature (Morris et al. 2007). An independent review of the impact of the floods that affected the UK in the summer of 2007 (Pitt 2008) recommended that more frequent and systematic monitoring of groundwater levels at times of high risk should be undertaken by the Environment Agency of England and Wales, and recognized a need for improved groundwater flood warning capability.

In many of the regions of the Chalk affected by groundwater flooding in the winter of 2000-2001, a sudden rise of the groundwater level was recorded just before the floods. Another common characteristic was the long duration of the flood events, which lasted weeks or months. Preliminary modelling (Pinault et al. 2005) and chemical investigations of different types of water (springs, rivers, groundwater) carried out by the Bureaude Recherches Géologiques et Minières (BRGM) in the Somme river catchment suggested that groundwater was a major contributor to the initiation and the persistence of these floods. Pinault et al. (2005) speculated that the sudden rise in groundwater levels immediately prior to the groundwater flooding event was associated with a significant change in the ability of the unsaturated zone to transmit water to the water table and that the prolonged nature of groundwater flooding on the Chalk was associated with extended periods of drainage from the unsaturated zone. Consequently, an important step in developing a flood warning system is to be able to understand and monitor changes in the matric potential of the unsaturated zone of the Chalk.

Groundwater movement in the unsaturated zone ofthe Chalk is primarily controlled by the nature of the porosity and is generally characterized by slow piston flow through the matrix and more rapid, 
although intermittent, bypass flow through fractures (Smith et al. 1970; Foster 1975; Downing et al. 1978, 1993; Gardner et al. 1990; Mathias et al. 2005; Ireson et al. 2006, 2009). In any season, unsaturated zone conditions also depend on antecedent moisture and current weather conditions. Additional control is given by the presence and nature of the soil and drift cover and weathered Chalk, which may play an important role in buffering the effects of rainfall, so leading to delayed recharge.

In situ measurements of hydraulic conductivity within the unsaturated zone have been made at several sites in SE England (Gardner et al. 1990). At matric potentials below about $-5 \mathrm{kPa}$ hydraulic conductivity was found to be almost constant, ranging between 1 and $6 \mathrm{~mm} \mathrm{day}^{-1}$ depending on the site. As potentials rose above- $5 \mathrm{kPa}$ (with decreasing pore water suction) hydraulic conductivity increased rapidly, with values in the range $100-1000 \mathrm{~mm}_{\text {day }}{ }^{-1}$. This increase in hydraulic conductivity was caused by the increasing contribution of the fracture network to the transmission of water as it became increasingly wetted.

The conclusion was that fractures start to become saturated only at potentials greater than c. $-5 \mathrm{kPa}$. Below this, the conductivity is that of the Chalk matrix; above it, water can move through both the matrix and the fracture system, and the conductivity increases accordingly. The frequency with which matric potentials exceed $-5 \mathrm{kPa}$ is therefore an important variable in determining whether rapid groundwater movement and recharge take place within the unsaturated zone in this region. Estimates of the relative proportion of recharge via fracture (bypass) flow compared with matrix flow vary from 10 to 30\% (Gardner et al. 1990; Jones \& Cooper 1998).

The debate on whether recharge occurs through matric flow or fracture flow, and the difficulty of reconciling conflicting observations, was moderated by the findings of Price et al. (2000), who concluded that fissure flow is not generated by water moving down a fissure from the soil but by the suction in surrounding blocks falling to a level where first the irregularities on the surfaces of the blocks are filled with water and then the narrower fissures also become filled. They also showed that the water store in these irregularities on the surfaces of blocks is a significant quantity and that, for the same water-table elevation, there will be significantly more storage in the unsaturated zone at the end of a recharge season than at the beginning of the following one.

The objective of the work reported here was to develop a new approach to the forecasting of groundwater flooding that would also minimize the occurrence of false alarms as it would take account of the state of the groundwater system as well as the severity of rainfall events. This would allow the authorities responsible for flood warning and relief to take more appropriate and timely decisions. This paper describes the work carried out to develop a fit-for-purpose early warning system for groundwater flooding for the Chalk using the Patcham area of Brighton as a test site.

\section{The Brighton study area}

The city of Brighton and Hove is located on the section of the South Downs that is bounded in the east by the River Ouse and the west by the River Adur and, in the context of groundwater resource management, is referred to as the Brighton Block (Jones \& Robins 1999; Fig. 1). Apart from the two bounding rivers, there are no perennial surface flows within the Brighton Block. The coast is mainly cliff-bound to the east of Brighton and flat-lying to the west. The South Downs are formed by southerly dipping Chalk rising to over $200 \mathrm{~m}$ above Ordnance Datum (aOD) in places at the escarpment, which is c. 8-10 km from the coast and overlooks the eroded Wealden anticline to the north.

The Chalk Group of the South Downs has traditionally been divided into three main units: the Lower Chalk (c. $70 \mathrm{~m}$ thick), the Middle Chalk (c. $80 \mathrm{~m}$ thick) and the Upper Chalk (c. $320 \mathrm{~m}$ thick). Reclassification of the Chalk (Bristow et al. 1998) subdivided these units into 10 members of more or less distinctive lithological character, each with its own hydraulic properties (Jones \& Robins 1999). The division of the previously uniform mass of Upper and Middle Chalk (now called the Sussex 
White Chalk) allows a better understanding of hydrogeological processes than was previously possible (Robins et al. 1999). There are also a number of persistent marl bands and hard grounds. The structural development of the Chalk of the South Downs has produced three distinct types of fractures: belts of intense vertical fractures; low-angle thrust joints; and high-angle shear joints. A detailed discussion of the hydrogeology of the South Downs, including the Brighton Block, has been given by Jones \& Robins (1999).

\section{Groundwater flooding in Brighton}

A report for Brighton and Hove City Council on the 2000-2001 floods (Binnie, Black \& Veatch 2001) includes a table of previous flood events in the Patcham area from 1958. Maps obtained from East Sussex County Council show the locations of groundwater emergence in the general Patcham area in 1877, 1913, 1915, 1916 and 1925. Although the authors are not aware of other flooding events in the Patcham area, the possibility that there have been more than those mentioned above should not be discounted.

It is evident that, because of the scale of construction, engineering works related to the building of the A27 and A23 dual carriageways will have significantly altered the surface and subsurface drainage of the area immediately north of Patcham. In the winter of 2000-2001 surcharging of sewers and flushing of storm drains resulted in local focusing of significant surface flooding; that is, the built environment had a significant effect that would have been very different from its impact in 1877. There are insufficient data to be able to evaluate whether flooding events prior to these major changes to the built environment were more or less severe (in either duration or flood volumes) than those that have occurred since their construction. However, Binnie, Black \& Veatch (2001) in discussing the 2000-2001 flooding event stated that although this is thought to represent the worst case of flooding of this type in the last 100 years, similar less severe flooding is likely to occur once every 20-25 years or so.

In the winter of 2000-2001 the Patcham area of Brighton was affected by serious flooding between 2 and 19 November 2000, which resulted in the closure of the London-Brighton railway line and the A23 road south of the A27. The ground floors of 15 houses were inundated, as well as the basements of several others. On 15 December further rainfall caused sewers to become surcharged. Rainfall in mid-February 2001 resulted in further basement flooding but no surface flooding. Excluding the cost of disruption to rail services, the total cost of the November flooding has been estimated at $£ 800000$ (Binnie Black \& Veatch 2001).

\section{The hydrological context of the 2000-2001 flooding event}

\section{Antecedent conditions}

The severity and extent of the 2000-2001 flooding in SE England can be attributed to the meteorological conditions during late 2000 and early 2001 coupled with, in some catchments, high antecedent groundwater levels. However, in the Brighton catchment, groundwater hydrographs show very little autocorrelation, typically only over a few months, and tend to show flashy behaviour at higher groundwater levels with limited variation in annual groundwater minima. These characteristics are entirely consistent with the Chalk having relatively well-developed and connected secondary fracture porosity in small catchments close to major discharge areas such as the coast. For example, the hydrograph for North Bottom Barn [TQ 322 118], Figure 2, is typically flashy and there is only a 3 month autocorrelation in groundwater levels at this site. The consequence of these aquifer characteristics in the Chalk of the Brighton Block is that the aquifer response to recharge and discharge is rapid, and groundwater levels generally return to similar conditions following the recession regardless of the amount of prior recharge.

\section{The rainfall event}


The most significant factor in the 2000-2001 floods was the rainfall. In the period from September 2000 to April 2001 there were eight successive months of exceptional rainfall. As a result, the southern region of the UK received 201\% of its long-term average (1961-1990) rainfall during September-December 2000. Long-term effective rainfall series suggest that, for Southern England at least, there is no recorded precedent for the magnitude of groundwater replenishment experienced over the extended 2000-2001 recharge season (Marsh \& Dale 2002).

\section{The groundwater response in Brighton to the 2000-2001 event}

The only location in the Brighton area where groundwater levels were being continuously monitored during 2000-2001 was Houndean Bottom [TQ 3930 1020] near Lewes (Binnie, Black \& Veatch 2001). The record shows that the first and largest rise in groundwater level occurred between 10 and 14 October 2000, when levels rose by $18.5 \mathrm{~m}$ in 4 days. The Chilgrove House borehole [SU 8356 1440], in the South Downs some $50 \mathrm{~km}$ to the west of Brighton, is the site of the longest unbroken sequence of groundwater level reading in the UK and possibly the world. The Hydrogeological Summary for the UK for December 2000 (CEH \& BGS 2000) ranked the level recorded at Chilgrove that month as the highest level of its 165 year period.

\section{Field data}

A field research and monitoring site was installed to the north of Patcham as part of this study. The equipment installed and the data collected have been described by Adams et al. (2008). A key element of the installation was a set of jacking tensiometers (Gallagher et al. 2011) capable of monitoring pressure head (matric potential) in the unsaturated zone at $5 \mathrm{~m}$ intervals from 15.5 to $60.5 \mathrm{~m}$ below surface.

Figure 3 displays the data from these jacking tensiometers. The deeper tensiometers were inundated during the winter periods but dried out in the summer, groundwaterlevel tending to return to a 'base level' of c. $72 \mathrm{~m}$ below surface. Figure 4 shows the detailed responses from before the onset of water table rise in December 2006 and December 2007. During both of these periods the $60 \mathrm{~m}$ tensiometer shows a rapid decrease in suction 10 days before the water table inundates it and 2 days before the water table starts to rise. This is consistent with CCTV observations (Adams et al. 2008), which imply a rapid wetting of the borehole walls at the start of a rise in groundwater level. Data on changes in the matric potential of the deep unsaturated zone are a key element of the early warning system developed for the Patcham area of Brighton. It is believed that this is the first time that such data have been used in this way.

\section{Modelling}

The flooding in the Brighton area in the winter of 2000 identified a need for predictive models of groundwater flooding events. Deterministic models have high predictive capability, but require relatively detailed conceptual models and they often need to be conditioned with extensive field observations. In contrast, statistical models generally require only relatively simple conceptual models and are less data intensive. Given the uncertainties regarding the detailed processes and ground conditions leading to the flooding event in the Brighton area and budgetary constraints, a statistical approach was used. Predictive modelling of high groundwater levels was based on the observation that the groundwater flooding event in Brighton, like other groundwater flooding elsewhere in the Chalk at that time, was associated with exceptionally high rainfall. However, high antecedent groundwater levels seen in the Somme Valley and other Chalk catchments in southern England were not observed in the Brighton Block prior to the flooding event. Probabilistic estimates of the occurrence of a given maximum groundwater level were derived from a distribution of cumulative rainfall between the annual groundwater level minima and maxima. Groundwater level data from a borehole at St. Peters Church, central Brighton [TQ 3150 0492] were used in the development of the model. This dataset was used as there was a relatively long historical record and the borehole is situated centrally within the Brighton Block. 


\section{Method}

A multiple linear regression model was developed to predict maximum annual groundwater levels. Annual groundwater level minima and the cumulative rainfall total between the annual minima and subsequent annual groundwater level maxima were taken as the two independent variables in the regression and the annual maximum groundwater level was taken to be the dependent variable. As with all regression models it is important first to establish that the independent variables are independent (that they are not co-correlated), that they show homeostasis and that they do not exhibit significant autocorrelation. The length of time between antecedent minima and groundwater level maxima could have been used in the regression. However, at St. Peters Church the cumulative rainfall total between the annual minima and maxima and the period between the annual minima and maxima are co-correlated so that the latter was not used in the regression model. Thus, the regression model was calibrated using monthly groundwater level data from the borehole at St. Peters Church, Brighton. The rainfall data were an average of rainfall data from four Environment Agency rain gauges (Falmer, Clayton Pumping Station, Patcham water works, and Plumpton) in or near Brighton. The model was calibrated for the period 1981-1998 and validated for the period 1998-2003.

\section{Results; model calibration and validation}

Based on the calibration the following linear regression model was obtained:

$$
h^{\max }=0.118 h^{\min }+0.0008 \sum_{t \max }^{t \min } P
$$

where $h^{\min }$ and $h^{\max }$ are the annual minimum and maximum groundwater levels, $P$ is the precipitation, and $t^{\min }$ and $t^{\max }$ are the times of the minimum and maximum levels.

The model had an adjusted $R^{2}$ of 0.99 and a standard error of estimate of 0.94 . Model validation was performed by substituting observed annual groundwater level minima and cumulative rainfall totals into the regression expression to calculate annual maxima.

The results of the model calibration and validation are shown in Figure 5. The monthly groundwater levels are shown in dark blue, the maximum annual groundwater levels from the calibration are shown in pink and the modelled maxima for the validation period, 1998- 2003 are shown in yellow. The model was calibrated on 17 years of data (1981-1998). To assess how sensitive the model is to any given year's observations, a leave-one out jack-knife assessment was performed. The coefficients of these 17 additional jack-knife regressions were used to predict groundwater levels from the validation period. They are shown in Figure 5 in pale blue and give an indication of the sensitivity of the model.

The model describes the maximum annual groundwater levels well, with the exception of winter 2000 where the model over-predicts the groundwater levels by about $3 \mathrm{~m}$. It is not clear why the model should over-predict groundwater levels in the winter of 2000. However, groundwater flooding during that period is expected to have caused groundwater discharge points that do not normally occur to become active. If this is the case then the relationships between groundwater level minima, maxima and cumulative rainfall may be non-linear and a linear model may not be so successful in representing the annual groundwater level maxima. However, as the figure shows that high annual maxima are consistently over- rather than under-pre ficted, the model should still be useful for predictive purposes.

\section{Results; model prediction}


How can the method be used to predict annual groundwater level maxima? Based on the calibrated regression model, once groundwater recession has stopped, and groundwater recharge exceeds the rate of discharge, the observed annual groundwater level minima can be used in conjunction with an estimate of rainfall for the coming season to predict the following annual maximum.

Three methods could be used to provide the rainfall prediction. The cumulative rainfall for a range of typical and atypical years could be used with the observed minima. For example, a 'worst-case scenario' could be to use the cumulative rainfall for the 2000 recharge event. In this way predicted maximum groundwater levels could be seen in the context of historic representative events. A second approach is to find the mean cumulative annual rainfall for the calibration period. Then, using the mean, a series of standard rainfall scenarios could be applied to the regression model (e.g. 50\%, 75\%, $125 \%$ and $150 \%$ of mean rainfall). By making a prediction based on these values a spread of representative maximum groundwater levels would be obtained. A third, probabilistic, approach would be to characterize the distribution of values of cumulative annual rainfall for the calibration period in terms of a mean and standard deviation. The probability that any specific groundwater level would be exceeded could then be determined by, for example, calculating the probability of exceedance directly from the mean and standard deviation or by using a Monte Carlo simulation to produce a probability distribution of predicted annual groundwater level maxima. This third approach has the benefit of providing a probabilistic prediction. The first approach is easiest to apply and communicate to nontechnical staff and the public, whereas the second approach allows reinterpretation of the prediction as the recharge season progresses.

For practical purposes, once a model has been calibrated and validated, it is recommended that it is periodically re-calibrated using all available data and the new regression then used for prediction. This is because regression models tend to improve with more cases (years).

In summary, this model allows maximum groundwater levels to be predicted up to a hydrometric season in advance. This method requires limited modelling expertise, can be run on a spreadsheet and needs only limited commonly available data. As such it is ideal as a first-tier screening for possible high groundwater level events and can be incorporated in regulating authorities' staged response and warning systems.

\section{The early warning system}

The proposed early warning system consists of a series of consecutive steps, some of which may overlap with each other in the timing of their operation. It involves the use of different models at different times and these models depend on data from the continued monitoring of groundwater levels, meteorological data (and monitoring of weather forecasts), and the matric potential within the unsaturated zone (using tensiometer data). The nature of the proposed early warning system is such that different models from those proposed here can be used within the same framework, thus allowing future development of the system as different techniques and data become available.

With continued use of the system, the operating agency will gain experience of catchment response and will be able to determine appropriate trigger levels for the instigation of both the different steps in the system and the different levels of alert. Thus the timings of the initiation of the different steps given here are only recommendations, and users must determine more appropriate ones for applications in their own areas. Equally, the timings of alerts, and indeed the nature of published alerts, must also be determined by the appropriate responsible authority.

\section{Preliminary step}

Initially, the nature of the catchment's response to recharge must be determined by consideration of the long-term hydrographs of various monitoring boreholes. If the hydrographs show that there is strong autocorrelation year on year then, as the next step of the system, in the summer months 
groundwater levels that are significantly above the average will be taken as an indication of an increased probability of groundwater flooding in the subsequent recharge season. In those catchments where there is little year-on-year autocorrelation (e.g. Brighton) then the lack of any above-average groundwater level does not have a bearing on the probability of subsequent groundwater flooding. This preliminary step is effectively a once-only determination, although it would be worth reassessing the determination every 5-10 years or so to see if hydrograph behaviour is changing for any reason.

\section{Step 1}

The determination of the catchment's response to recharge (preliminary step) is a once-only determination and thus the early warning system will normally be initiated in the summer months by consideration of the hydrographs of the key monitoring boreholes to see if groundwater levels are significantly above average. Even in those catchments, such as Brighton, where hydrograph response year on year is such that summer groundwater levels return to a similar level, summer levels should still be monitored for any signs of unusual behaviour including an early onset of the recharge season. However, it is worth noting that even in the summer of 2000 the Brighton catchment gave no indication of the year on year increase in base level recorded in some other catchments in the English Chalk (e.g. Robinson et al. 2001). Any indication of above-average groundwater levels indicates that subsequent winter groundwater levels will possibly be higher than average for average subsequent rainfall-recharge. Should subsequent rainfall-recharge be higher than average then the probability of groundwater flooding is increased. Step 2 is initiated once recharge has commenced, thus allowing the minimum seasonal groundwater level at one or more key observation boreholes to be identified.

\section{Step 2}

Following the onset of recharge, and the identification of the minimum groundwater level for the current year, a statistical model to predict maximum groundwater levels at one or more key observation boreholes based on antecedent groundwater levels and assumptions about future rainfall is applied. The multiple linear regression method has been described above; annual groundwater level minima and the cumulative rainfall total between the annual minima and subsequent annual groundwater level maxima are taken as the two independent variables in the regression and the annual maximum groundwater level is taken to be the dependent variable.

Thus once this model has been run for a range of future rainfall scenarios, monitoring of the actual cumulative rainfall and reference to the model results will indicate what the resultant groundwater level might be. It must, of course, be realized that this approach does not directly indicate the likelihood of groundwater flooding, but rather indicates what subsequent groundwater levels might be. The predicted groundwater levels need to be compared with those of previous flood events (e.g. as recorded in 2000-2001) to assess the likelihood of groundwater flooding.

\section{Step 3}

To some extent, the results from the application of the statistical model of the second step will determine the time of initiation of the third step. However, the third step is effectively running in the background at all times, as it involves the monitoring of changes in the matric potential (i.e. suction) of the unsaturated zone. Once the unsaturated zone reaches a critical potential, the groundwater table rises rapidly and this can give rise to groundwater flooding. Thus, once this critical level is reached, the monitoring agency should be ready to raise the level of alert to those parties who would be affected by any groundwater flooding. Once this third step has been initiated the fourth step must be run in parallel with it. As noted above, the Brighton catchment showed a rapid decrease in matric suction 2 days before the water table started to rise; other catchments might show a different time response.

\section{Step 4}


This step involves the monitoring of local weather forecasts. Any storm events that may occur in the catchment(s) concerned will have a significant effect on recharge and, depending on the state of the aquifer and the predicted magnitude of any forecast storm, it may be necessary to raise the level of alert even further.

It should be noted that in many catchments intense rainfall events of long duration may result in surface runoff flooding and will increase the possibility of groundwater flooding at almost any time. Therefore, weather forecasts should, of course, be monitored throughout the year for indications of extreme rainfall events that will affect the groundwater regime.

\section{Timings of levels of alert}

The following are only suggestions as to when the level of alert should be raised. Also, no indication is given of the nature of the alert that should be given to the public at any particular level; this is for the monitoring agency to determine.

- Level 1. This is the normal situation when there is no indication that there will be any flooding in the coming winter.

- Level 2. This is the level of alert when summer groundwater levels are significantly higher than average (trigger level to be determined by operating agency) and/or the recharge season has started significantly earlier than average (date to be determined by operating agency).

- Level 3. This level is initiated when the statistical modelling indicates that there is a significantly higher than average probability that groundwater levels will rise to levels equal to those recorded during previous groundwater flood events; for example, that of 2000- 2001 (trigger probability value to be determined by operating agency).

- Level 4. To be initiated when the matric potential in the unsaturated zone (if it is being monitored) is seen to reach a critical value (to be determined by operating agency) and/or the weather forecasting agencies are predicting imminent storm events in the catchment(s).

- Level 5. The ultimate level of alert issued if level 4 has been achieved and the weather forecasting agencies are predicting imminent storm events in the catchment(s) and/or critical matric potentials in the unsaturated zone have been achieved, but groundwater levels have not yet

- risen to flood event levels.

Although the early warning system has been described as a series of steps, it must be realized that, in many catchments, extreme storm events at any time of the year may in some circumstances give rise to groundwater flooding. Thus warnings may need to be raised to Level 4 or 5 should major storm events be predicted; again, this will depend to some extent on the experience of the monitoring or operating agency.

\section{Further development of early warning systems for groundwater flooding}

The system as described is qualitative in its current state and this is due to the fact that it has not been possible to test the system in practice as there has been no groundwater flooding event in Patcham since its development. As the system is used, the experience so gained will allow the operating agency to develop appropriate quantitative measures to replace the qualitative aspects. However, it will be necessary to constantly review such quantitative elements, as they will need to be refined with time as the experience of use increases.

There is no reason why this system should not be translated to other chalk groundwater systems that are prone to groundwater flooding. It is recommended that this should be done on no greater than a catchment scale and, where there is much hydrogeological variation, on a sub-catchment scale. It will also be necessary to identify appropriate groundwater level monitoring points for each (sub-) catchment with their own appropriate trigger values for matric potential and groundwater levels. 


\section{Conclusions}

A framework method has been developed for an early warning system for groundwater flooding in chalk catchments. Initially, it is recommended that it should be applied to the Brighton catchment, as there is an identified need for it and, as a result of the study reported here, there is an appropriate infrastructure to support it. A unique element of the approach described in this paper is the use of data showing changes in the matric potential of the deep unsaturated zone of the Chalk. However, the framework approach described can still be applied to areas where groundwater flooding may occur, but where such data are not available. There is scope for further development of this application and this will depend upon a number of factors, not least the degree to which it is applied in Brighton.

The approach described in this paper provides a framework within which different models are applied to the available data. With time, more and possibly different data will become available. Also, the models described can be refined and new models developed, thus allowing the new and/or improved models to be used within the given framework. The framework can also be used in other areas of the Chalk where different models may have been developed and these models can be used as appropriate within such a framework.

\section{Acknowledgements.}

This work was carried out as part of the FLOOD 1 project funded under the INTERREG IIIA initiative of the European Union. It was led by the French Geological Survey (BRGM) and included the University of Brighton (UK project manager) and the British Geological Survey. The INTERREG authority supported $50 \%$ of the costs with the remainder of the funding being provided by the three project partners and the project's commercial partners. The authors would like to acknowledge the assistance provided by their commercial partners, who provided both funding-in- kind and membership of the Project Advisory Group. They were: Black \& Veatch, Brighton \& Hove City Council, East Sussex Fire \& Rescue Service, Environment Agency, Channel Tunnel Rail Link (Union Railways North Ltd.), Halcrow, Highways Agency, Lewes District Council, Southern Testing, Southern Water, Conseil Général de la Somme, Conseil Régional de Picardie and DIREN Picardie. This paper is published by permission of the Director, British Geological Survey (NERC).

\section{References}

ADAMS, B., BLOOMFIELD, J., GALLAGHER, A., JACKSON, C., RUTTER, H.\&WILLIAMS, A. 2008. FLOOD 1 Final Report. British Geological Survey Open Report, OR/08/055.

BINNIE, BLACK, \& VEATCH, 2001. Flood defence assessment of downland flooding. Report for Brighton and Hove Council.

CEH, \& BGS, 2000. The Hydrological Summary for the United Kingdom, December 2000. National Water Archive, CEH Wallingford (NERC).

BRISTOW, R., MORTIMORE, R. \& WOOD, C. 1998. Lithostratigraphy for mapping the Chalk of southern England. Proceedings of the Geologists’ Association, 109, 293-315.

DOWNING, R.A., SMITH, D.B.\&WARREN, S.C. 1978. Seasonal variations of tritium and other constituents in groundwater in the Chalk near Brighton, England. Journal of the Institution of Water Engineers and Scientists, 32, 123-136.

DOWNING, R.A., PRICE,M. \& JONES, G.P. 1993. The making of an aquifer. In: DOWNING, R.A., PRICE, M. \& JONES, G.P. (eds) The Hydrogeology of the Chalk of North-west Europe. Clarendon Press, Oxford, 1-13. 
FOSTER, S.S.D. 1975. The Chalk groundwater tritium anomaly—a possible explanation. Journal of Hydrology,25, 159-165.

GALLAGHER, A., BUCKLEY, D.K., MOLYNEUX, I. \& RUTTER, H. 2011. Geological controls on groundwater storage and recharge of the Chalk aquifer of southern England. Quarterly Journal of Engineering Geology and Hydrogeology (inreview).

GARDNER, C.M.K., COOPER, J.D., WELLINGS, S.R., BELL, J.P.,HODNETT, M.G., BOYLE, S.A. \& HOWARD, M.J. 1990. Hydrology of the unsaturated zone of the chalk of southeast England. In: BULAND, J.B., CORBETT, B.O., JONES, D.L., MORTIMORE, R.N. \& ROBERTS, T.S. (eds) Chalk. Thomas Telford, London, 611-618.

IRESON, A.M., WHEATER, H.S., BUTLER, A.P., MATHIAS, S.A., FINCH, J. \& COOPER, J.D. 2006. Hydrological processes in the Chalk unsaturated zone-Insights from an intensive field monitoring programme. Journal of Hydrology, 330, 29-43.

IRESON, A.M., MATHIAS, S.A., WHEATER, H.S., BUTLER, A.P. \& FINCH, J. 2009. A model of flow in the chalk unsaturated zone incorporating progressive weathering. Journal of Hydrology, 365, 244-260.

JONES, H.K.\&COOPER, J.D. 1998. Water transport through theunsaturated zone of the Middle Chalk: a case study from Fleam Dyke lysimeter. In: Robins, N.S. (ed.) Groundwater Pollution, Aquifer Recharge and Vulnerability. Geological Society, London, Special Publications, 130, 117128.

JONES, H.K. \& ROBINS, N.S. 1999. The Chalk aquifer of the South Downs. Hydrogeological Report of the British Geological Survey.

MARSH, T.J.\&DALE, M. 2002. The UK floods of 2000-2001: a hydrometeorological appraisal. Journal of CIWEM, 16, 180-188.

MATHIAS, S.A., BUTLER, A.P., MCINTYRE, N.\&WHEATER, H.S. 2005. The significance of flow in the matrix of the Chalk unsaturated zone. Journal of Hydrology, 310, 62-77.

MORRIS, S.E., CORBY, D. \& PARKES, A. 2007. Towards groundwater flood risk mapping. Quarterly Journal of Engineering Geology and Hydrogeology, 40, 203-211.

PINAULT, J.-L., AMRAOUI, N.\&GOLAZ, C. 2005. Groundwater induced flooding in macroporedominated hydrological system in the context of climate changes. Water Resources Research, 41, W05001, doi:10.1029/2004WR003169.

PITT, M. 2008. The Pitt review: Learning lessons from the 2007 floods. Cabinet Office, London. http://archive.cabinet office.gov.uk/pittreview/thepittreview/final_report.html.

PRICE, M., LOW, R.G. \& MCCANN, C. 2000. Mechanisms of water storage and flow in the unsaturated zone of the Chalk aquifer. Journal of Hydrology, 233, 54-71.

ROBINS, N.S., JONES, H.K. \& ELLIS, J. 1999. An aquifer management case study-the Chalk of the English South Downs. Water Resources Management, 13, 205-218.

ROBINSON, V.K., SOLOMON, J.\& MORRIS, S. 2001. Groundwater flooding in the Thames Region, winter 2000-2001. Thames Region, Environment Agency, Reading.

SMITH, D.B., WEARN, P.L., RICHARDS, H.G. \& ROWE, P.C. 1970. Water movement in the unsaturated zone of high and low permeability strata using natural tritium. In: Isotope Hydrology. 
International Atomic Energy Agency conference proceedings, Vienna 6-13 March, report no. STI/PUB/255, 73-87. 


\section{Figures}

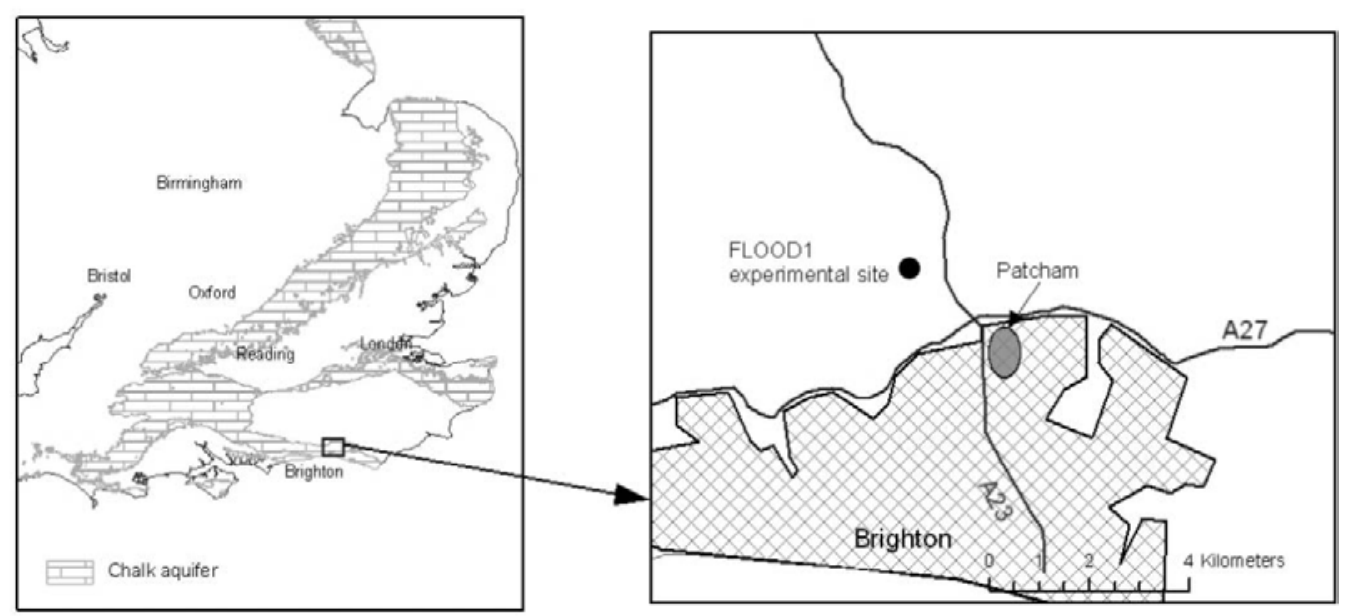

Figure 1. Location of the Patcham area of Brighton and the FLOOD 1 research site.

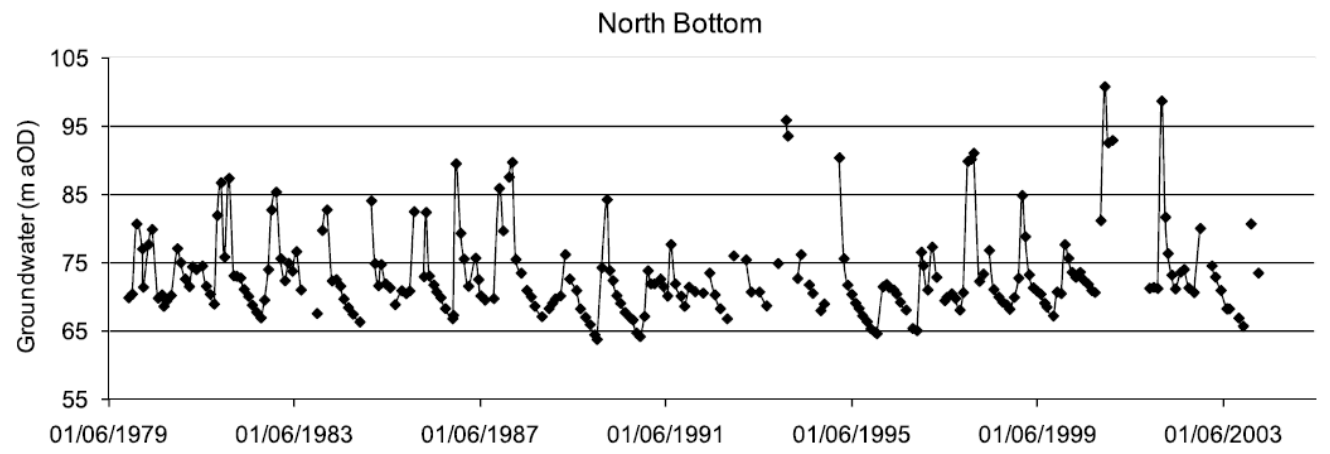

Figure 2. Hydrograph of the North Bottom Barn borehole [TQ 322118]

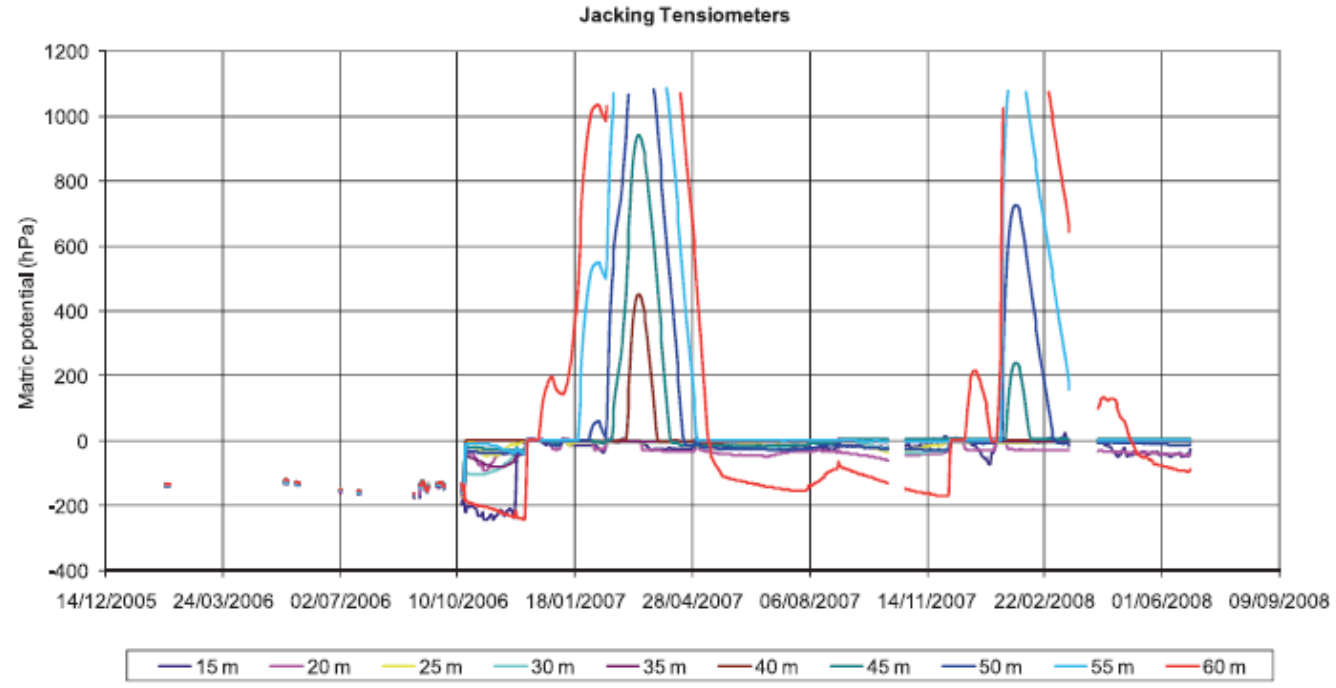

Figure 3. Data from the jacking tensiometers in NHB2 borehole. 



01/11/2006 11/11/2006 21/11/2006 01/12/2006 11/12/2006 21/12/2006 31/12/2006 01/11/2007 11/11/2007 21/11/2007 01/12/2007 11/12/2007 21/12/2007 31/12/2007

$-15 \mathrm{~m}-20 \mathrm{~m}-25 \mathrm{~m}-30 \mathrm{~m}-35 \mathrm{~m}-40 \mathrm{~m}-45 \mathrm{~m}-50 \mathrm{~m}-55 \mathrm{~m}-60 \mathrm{~m}-\cdots$ Water level

Figure 4. Jacking tensiometer data from the NHB2 borehole showing rapid change in suction prior to water level rise.



Figure 5. Results of the linear regression model for St. Peters Church, Brighton. The monthly groundwater levels are shown in dark blue, the maximum annual groundwater levels from the calibration are shown in pink and the modelled maxima for the validation period, 1998-2003, are shown in yellow. The pale blue indicates the sensitivity of the regression model based on jack-knife re-sampling. 